Published in final edited form as:

Neurobiol Aging. 2017 August ; 56: 212.e1-212.e3. doi:10.1016/j.neurobiolaging.2017.03.014.

\title{
TMEM230 IN PARKINSON'S DISEASE
}

\section{Laura Ibanez $^{1}$, Umber Dube ${ }^{1,2}$, John Budde ${ }^{1}$, Kathleen Black ${ }^{1}$, Alexandra Medvedeva ${ }^{1}$,} Albert A. Davis ${ }^{3}$, Joel S. Perlmutter ${ }^{3}$, Bruno A. Benitez ${ }^{4}$, and Carlos Cruchaga ${ }^{1,5}$

${ }^{1}$ Department of Psychiatry, School of Medicine, Washington University in Saint Louis - 660 South Euclid Avenue Saint Louis, MO 63110

${ }^{2}$ Medical Scientist Training Program, School of Medicine, Washington University in Saint Louis 660 South Euclid Avenue Saint Louis, MO 63110

${ }^{3}$ Department of Neurology, School of Medicine, Washington University in St Louis, - 660 South

Euclid Avenue Saint Louis, MO 63110

${ }^{4}$ Department of Medicine, School of Medicine, Washington University in Saint Louis - 660 South Euclid Avenue Saint Louis, MO 63110

${ }^{5}$ Hope Center Program on Protein Aggregation and Neurodegeneration, Washington University in Saint Louis - 660 South Euclid Avenue (Campus Box 8134) Saint Louis, MO 63110

\section{Abstract}

A study on familial Parkinson disease (PD) described four variants in the gene TMEM230 (Chr. 20p13) as cause of PD (1). The aim of this study was to test if variants in the TEMEM230 gene are associated with PD in two independent American European datasets. No variants in the TMEM230 region were found associated with PD, age at onset or cerebrospinal fluid a-synuclein levels.

Parkinson Disease (PD) is the second most common neurodegenerative disorder after Alzheimer Disease (2), yet the cause of the majority of PD cases remains unknown. Several studies have described genetic variants associated with the disease [reviewed by (3)]. Although the monogenic forms of PD are rare (5-10\%), their study has led to the finding of important genes and genetic variants that in some cases have also been found to be involved in the sporadic cases (3). Recently, a study with familial PD described several mutations in the gene TMEM230 (Chr. 20p13) (1). However, at least one independent study in Caucasian population thus far failed to find an association of TMEM230 variants and unrelated PD cases (4). The DNAJC13 gene, p.N855S mutation was suggested to cause autosomal dominant late-onset PD and to co-segregate with PD within five families of Dutch-GermanRussian Mennonite origin from Saskatchewan and British Columbia, albeit with incomplete penetrance and with phenocopies (5). The same group reported that rare variants in

Correspondence to: Carlos Cruchaga, PhD, Washington University School of Medicine, 660 South Euclid Avenue, Campus Box 8134, Saint Louis, MO 63110.

Publisher's Disclaimer: This is a PDF file of an unedited manuscript that has been accepted for publication. As a service to our customers we are providing this early version of the manuscript. The manuscript will undergo copyediting, typesetting, and review of the resulting proof before it is published in its final citable form. Please note that during the production process errors may be discovered which could affect the content, and all legal disclaimers that apply to the journal pertain. 
DNAJC13 were associated with increased or decreased risk for developing PD in Caucasian Canadian and Norwegian populations (6). However, subsequent studies in Chinese, Caucasian or French-Canadian/French populations found no mutations or variants in DNAJC13 associated with PD (7-11). These findings have deeply questioned the genetic role of DNAJC13 gene in PD. In addition, the pathogenic mutations in the TMEM230 gene were reported in the same original Saskatchewan family (1). However, a close look at the initial report of TMEM230 in PD revealed an unusual large number of unaffected mutation carriers, the lack of mutations that co-segregate with PD in independent families and a high occurrence of homozygous mutations among Chinese patients in a dominantly inherited disorder (1) (Farrer et al., 2017 - unpublished data). In addition, an increasing number of negative reports in both Chinese and Caucasian populations have also questioned the role of TMEM230 mutations both in the general population and in families with autosomal dominant PD (12-15). The aim of this study was to test the association of TMEM230 with $\mathrm{PD}$ in two independent cohorts. We also tested the potential association of these variants with cerebrospinal fluid (CSF) a-synuclein levels or age at onset using survival analysis.

We used two large European Ancestry PD datasets: GWAs data and DNA from the Washington University in Saint Louis (WUSTL) Movement Disorder Clinic (MO, USA) (16) and GWAs and Whole Exome Sequencing (WES) data from the Parkinson's Progression Markers Initiative (PPMI) consortium (www.ppmi-info.org). This study was approved by the Washington University in Saint Louis Institutional Review Board and the Human Research Protection Office (approval number: 201107095). PD clinical diagnoses were based on UK Brain Bank criteria (17). Population baseline characteristics have been previously described $(18,19)$. In summary, the WUSTL dataset contains 499 PD cases and 294 healthy controls, with $41.61 \%$ females. The PPMI dataset is smaller, 340 PD cases and 140 healthy controls with $34.38 \%$ females. We genotyped the variants described by Deng et al. (1) in the WUSTL dataset. WES data were downloaded from the PPMI web page, then standard quality control filters were applied $(18,20)$.

\section{PPMI Dataset}

The variants corresponding to the TMEM230 region were annotated using SNPEff (21). Then, we used plink1.9 (22) to test the possible association between each of the TMEM230 variants and PD status (diagnosis), CSF a-synuclein levels, and age at onset correcting for age, sex, and the first two principal components. Bonferroni correction for multiple comparisons was also applied. To assess the possible association of the TMEM230 region with PD status we performed a gene-based analysis including only non-synonymous variants with a MAF $<1 \%$ and using SKAT (23). To run the survival analysis for age at onset we only included non-synonymous variants with $\mathrm{MAF}<1 \%$ and applied a CMC burden test modification. Briefly, we added the allele counts for each individual and used that count to perform the survival analysis correcting for sex and the first two principal components. We also have compared the variance burden of the gene region between the WES data and the ExAC non-Finnish database (24).

Seventeen variants were found in the PPMI WES dataset. One variant ( $r s 45610034 ; \mathrm{p}=0.02$ ) located on the $3^{\prime}$ UTR was nominally associated with PD risk and another one 
(chr20:5081276:G:A; $\mathrm{p}=0.05$ ) also in the same region was associated with age at onset, although none of them passed the multiple test correction threshold. No variants were associated with CSF a-synuclein level. The gene based analysis with the three variants annotated as loss-of-function using SKAT Binary revealed that the region was not associated with PD status, a-synuclein levels or age at onset in our dataset. When comparing the cMAF (cumulative minor allele frequency) TMEM230 region with the cMFAf ound in the ExAC database for the same region, the PPMI dataset does not seem to be enriched in TMEM230 variants compared with the non-Finnish population of ExAC (data not shown). We also genotyped using KASPar methodology the four TMEM230 variants described by Deng et al. We did not find any carriers in the WUSTL cohort composed of 499 PD cases and 294 healthy controls.

Due to the controversial results on the DNAJC13 gene, p.N855S mutation findings (5), we also compared the cMAF in the PPMI dataset with the cMAF in ExAC for DNAJC13. The PPMI dataset is not enriched in variants in the DNAJC13 region compared with the nonFinnish European ExAC population (data not shown). Moreover, the mutation p.N855S was not present in the ExAC or the PPMI databases.

In conclusion, our results do not support a role of genetic variants in either TMEM230 or DNAJC13 in PD risk. However, the investigated cohorts are mainly composed by sporadic unrelated PD cases (10\% had family history) whereas the cohorts from Deng et al are mainly family based. Thus the described variants could be genotyping errors as suggested by Farrer et al (http://www.biorxiv.org/content/early/2017/01/01/097030) or very rare and relate only to familial forms of PD. The later is supported by two variants reaching significant $\mathrm{p}$-values in their association with PD status or age at onset in the TMEM230 region in the studied cohort. In summary, TMEM230 may represent a new candidate gene for PD that should be further investigated in larger sporadic and familial cohorts.

\section{Supplementary Material}

Refer to Web version on PubMed Central for supplementary material.

\section{Acknowledgments}

This work was supported by grants from NINDS (NS075321, NS41509, NS058714, and R01-AG035083); the Barnes-Jewish Hospital Foundation (BJHF); the American Parkinson Disease Association (APDA) Advanced Research Center for Parkinson Disease at Washington University in St. Louis; the Greater St. Louis Chapter of the APDA; the Barnes-Jewish Hospital Foundation (Elliot Stein Family Fund and Parkinson Disease Research Fund), The Michael J. Fox Foundation for Parkinson's Research, Alzheimer's Association and Weston Brain Institute (BAND-14-338165). The authors thank the Parkinson's Progression Markers Initiative (PPMI) project for granting access to data used in the preparation of this article. PPMI did not participate in the analyses or writing of this manuscript.

\section{References}

1. Deng HX, Shi Y, Yang Y, Ahmeti KB, Miller N, Huang C, et al. Identification of TMEM230 mutations in familial Parkinson's disease. Nat Genet. 2016; 48(7):733-9. [PubMed: 27270108]

2. de Lau LM, Breteler MM. Epidemiology of Parkinson's disease. The Lancet Neurology. 2006; 5(6): 525-35. [PubMed: 16713924] 
3. Kalinderi K, Bostantjopoulou S, Fidani L. The genetic background of Parkinson's disease: current progress and future prospects. Acta Neurol Scand. 2016; 134(5):314-26. [PubMed: 26869347]

4. Giri A, Mok KY, Jansen I, Sharma M, Tesson C, Mangone G, et al. Lack of evidence for a role of genetic variation in TMEM230 in the risk for Parkinson's disease in the Caucasian population. Neurobiology of aging. 2016

5. Vilarino-Guell C, Rajput A, Milnerwood AJ, Shah B, Szu-Tu C, Trinh J, et al. DNAJC13 mutations in Parkinson disease. Hum Mol Genet. 2014; 23(7):1794-801. [PubMed: 24218364]

6. Gustavsson EK, Trinh J, Guella I, Vilarino-Guell C, Appel-Cresswell S, Stoessl AJ, et al. DNAJC13 genetic variants in parkinsonism. Movement disorders : official journal of the Movement Disorder Society. 2015; 30(2):273-8. [PubMed: 25393719]

7. Foo JN, Liany H, Tan LC, Au WL, Prakash KM, Liu J, et al. DNAJ mutations are rare in Chinese Parkinson's disease patients and controls. Neurobiology of aging. 2014; 35(4):935 e1-2.

8. Lorenzo-Betancor O, Ogaki K, Soto-Ortolaza AI, Labbe C, Walton RL, Strongosky AJ, et al. DNAJC13 p.Asn855Ser mutation screening in Parkinson's disease and pathologically confirmed Lewy body disease patients. European journal of neurology. 2015; 22(9):1323-5. [PubMed: 26278106]

9. Ross JP, Dupre N, Dauvilliers Y, Strong S, Ambalavanan A, Spiegelman D, et al. Analysis of DNAJC13 mutations in French-Canadian/French cohort of Parkinson's disease. Neurobiology of aging. 2016; 45:212 e13-7.

10. Quadri M, Breedveld GJ, Chang HC, Yeh TH, Guedes LC, Toni V, et al. Mutations in TMEM230 are not a common cause of Parkinson's disease. Movement disorders : official journal of the Movement Disorder Society. 2017

11. Wu H, Zheng X, Xie F, Cen Z, Chen Y, Lu X, et al. Genetic analysis of the TMEM230 gene in Chinese patients with familial Parkinson disease. Parkinsonism \& related disorders. 2016

12. Giri A, Mok KY, Jansen I, Sharma M, Tesson C, Mangone G, et al. Lack of evidence for a role of genetic variation in TMEM230 in the risk for Parkinson's disease in the Caucasian population. Neurobiology of aging. 2017; 50:167 e11-e13.

13. Yan W, Tang B, Zhou X, Lei L, Li K, Sun Q, et al. TMEM 230 mutation analysis in Parkinson's disease in a Chinese population. Neurobiology of aging. 2017; 49:219 e1-e3.

14. He YC, Li QQ, Huang P, Sun Q, Li DH, Wang T, et al. TMEM230 stop codon mutation is rare in parkinson's disease and essential tremor in eastern China. Movement disorders : official journal of the Movement Disorder Society. 2016

15. Baumann H, Wolff S, Munchau A, Hagenah JM, Lohmann K, Klein C. Evaluating the role of TMEM230 variants in Parkinson's disease. Parkinsonism \& related disorders. 2016

16. Buddhala C, Campbell MC, Perlmutter JS, Kotzbauer PT. Correlation between decreased CSF alpha-synuclein and Abeta(1)(-)(4)(2) in Parkinson disease. Neurobiology of aging. 2015; 36(1): 476-84. [PubMed: 25212463]

17. Hughes AJ, Daniel SE, Kilford L, Lees AJ. Accuracy of clinical diagnosis of idiopathic Parkinson's disease: a clinico-pathological study of 100 cases. Journal of neurology, neurosurgery, and psychiatry. 1992; 55(3):181-4.

18. Davis AA, Andruska KM, Benitez BA, Racette BA, Perlmutter JS, Cruchaga C. Variants in GBA, SNCA, and MAPT influence Parkinson disease risk, age at onset, and progression. Neurobiology of aging. 2016; 37:209 e1-7.

19. Weintraub D, Papay K, Siderowf A, Parkinson's Progression Markers I. Screening for impulse control symptoms in patients with de novo Parkinson disease: a case-control study. Neurology. 2013; 80(2):176-80. [PubMed: 23296128]

20. Benitez BA, Davis AA, Jin SC, Ibanez L, Ortega-Cubero S, Pastor P, et al. Resequencing analysis of five Mendelian genes and the top genes from genome-wide association studies in Parkinson's Disease. Molecular neurodegeneration. 2016; 11:29. [PubMed: 27094865]

21. Cingolani P, Platts A, Wang le L, Coon M, Nguyen T, Wang L, et al. A program for annotating and predicting the effects of single nucleotide polymorphisms, SnpEff: SNPs in the genome of Drosophila melanogaster strain w1118; iso-2; iso-3. Fly (Austin). 2012; 6(2):80-92. [PubMed: 22728672] 
22. Chang CC, Chow CC, Tellier LC, Vattikuti S, Purcell SM, Lee JJ. Second-generation PLINK: rising to the challenge of larger and richer datasets. Gigascience. 2015; 4:7. [PubMed: 25722852]

23. Wu MC, Lee S, Cai T, Li Y, Boehnke M, Lin X. Rare-variant association testing for sequencing data with the sequence kernel association test. Am J Hum Genet. 2011; 89(1):82-93. [PubMed: 21737059]

24. Lek M, Karczewski KJ, Minikel EV, Samocha KE, Banks E, Fennell T, et al. Analysis of proteincoding genetic variation in 60,706 humans. Nature. 2016; 536(7616):285-91. [PubMed: 27535533] 